The Federal Reserve BanK of Kansas City ECONOMIC RESEARCH DEPARTMENT

Labor Market Search, the Taylor Principle, and Indeterminacy

Takushi Kurozumi and Willem Van Zandweghe October 2010 RWP 11-01 


\title{
Labor Market Search, the Taylor Principle, and Indeterminacy*
}

\author{
Takushi Kurozumi $^{\dagger}$ \\ Willem Van Zandweghe
}

October 2010

RWP 11-01

\begin{abstract}
In a sticky-price model with labor market search and matching frictions, forecast-based interest rate policy almost always induces indeterminacy when it is strictly inflation targeting and satisfies the Taylor principle. Indeterminacy is due to a vacancy channel of monetary policy that makes inflation expectations self-fulfilling. The effect of this channel strengthens as the sluggishness of the adjustment of employment relative to that of consumption increases. When this relative sluggishness is high, the Taylor principle fails to ensure determinacy, regardless of whether the policy is forecast-based or outcome-based, whether it is strictly or flexibly inflation targeting, or contains policy rate smoothing.
\end{abstract}

JEL Classification: E24; E52

Keywords: Labor market search and matching frictions; Interest rate policy; Taylor principle Indeterminacy of equilibrium; Vacancy channel of monetary policy

\footnotetext{
* The authors are grateful for discussions and comments from James Bullard, Miguel Casares, Kai Christoffel, Daniele Coen-Pirani, Riccardo DiCecio, John Duffy, Huberto Ennis, Marvin Goodfriend, Robert King (the editor), Michael Krause, Thomas Lubik, Bennett McCallum, Alexander Wolman, and two anonymous referees, as well as participants at Midwest Macroeconomics Meetings 2007, EEAESEM 2007, Federal Reserve System Conference on Macroeconomics 2008, North American Summer Meeting of the Econometric Society 2008, Learning Week 2008, BIS, Bank of Canada, ECB, Kansas City Fed, Richmond Fed, Portland State University, University of Notre Dame, and West Virginia University. The views expressed herein are those of the authors and should not be interpreted as those of the Bank of Japan, the Federal Reserve Bank of Kansas City or the Federal Reserve System.

Bank of Japan, E-mail address: takushi.kurozumi@boj.or.jp.

$\$$ Corresponding author. Research Department, Federal Reserve Bank of Kansas City, 1 Memorial Drive, Kansas City, MO 64198, USA. Tel.: +1 8168812766 E-mail: willem.vanzandweghe@kc.frb.org.
} 


\section{Introduction}

The recent literature has incorporated labor market search and matching frictions along the lines of Mortensen and Pissarides (1994) into sticky-price models and has investigated their implications for inflation dynamics (e.g. Walsh, 2005; Krause and Lubik, 2007; Sveen and Weinke, 2009; Trigari, 2009; Van Zandweghe, 2010) and for optimal monetary policy (e.g. Thomas, 2008; Faia, 2009; Ravenna and Walsh, 2010). However, there has been no research analyzing the effect of these labor market frictions on the Taylor principle. ${ }^{1}$ This paper examines the implications for interest rate policy in terms of (local) equilibrium determinacy. Several specifications of the policy are studied: forecast-based or outcome-based, strictly or flexibly inflation targeting, or containing policy rate smoothing.

The main results of the paper are twofold. First, the forecast-based policy almost always induces indeterminacy when it is strictly inflation targeting and satisfies the Taylor principle. This result is in stark contrast to those of previous studies with a frictionless labor market (e.g. Bullard and Mitra, 2002; Woodford, 2003). Second, when the sluggishness of the adjustment of employment relative to that of consumption is high within ranges of parameter values calibrated in the literature, the Taylor principle fails to ensure determinacy, regardless of whether interest rate policy is forecast-based or outcome-based or whether it is strictly or flexibly inflation targeting or contains policy rate smoothing.

Why does the active strictly inflation-forecast targeting policy make determinacy almost impossible? This is due to a vacancy channel of monetary policy that stems from the labor market search and matching frictions and that makes inflation expectations self-fulfilling. The labor market frictions result in firms' sluggish adjustment of employment. As a consequence, interest rate policy is transmitted by the vacancy channel in addition to the conventional aggregate demand channel that is the only channel in the absence of the labor market frictions. One point we emphasize here is that these two channels have opposing effects on inflation.

As usual, the aggregate demand channel leads a higher real interest rate to reduce inflation. By contrast, the vacancy channel causes a rise in the real interest rate to increase inflation. This is because

\footnotetext{
${ }^{1}$ After the working-paper version of this paper (Kurozumi and Van Zandweghe, 2008), there emerged two related papers, Tesfaselassie and Schaling (2009) and Rannenberg (2009), both of which employ Blanchard and Galí (2010)'s sticky-price model with hiring costs. In this model, Tesfaselassie and Schaling find that the hiring costs limit the size of the policy response to unemployment that ensures determinacy. Rannenberg introduces skill decay during unemployment into the model and analyzes its implications for the Taylor principle.
} 
a real interest rate rise, by dampening consumption demand, reduces firms' current vacancy posting and hence lowers the level of employment available for production in current and subsequent periods. Hence, the interest rate rise lowers future output supply. At the same time, such a rate rise prompts households to substitute current with future consumption, and thus firms expect consumption demand to recover after its current decline. From this expected rise in future demand and the diminished future supply, firms anticipate a strong expansion of future vacancy posting. This raises expected future real marginal cost via an equilibrium job creation condition, and hence expected future inflation via the New Keynesian Phillips curve. Therefore, the vacancy channel leads a rise in the real interest rate to increase expected future inflation. This makes inflation expectations self-fulfilling under active policy responses solely to expected future inflation, thereby inducing indeterminacy.

The effect of the vacancy channel becomes stronger as the sluggishness of the adjustment of employment relative to that of consumption increases. In such a case, output supply adjusts more slowly to changes in consumption demand. Consequently, when that relative sluggishness is high, determinacy is ensured only by interest rate policy that fails to meet the Taylor principle. This is because when the real interest rate declines in response to a rise in inflation expectations, it yields a temporary increase in consumption demand. Hiring increases in response and the anticipation of a decline in future consumption in the face of elevated future employment lowers expected future real marginal cost. The resulting reduction in expected future inflation prevents the initial inflationary expectations from becoming self-fulfilling, and thus a determinate equilibrium is generated.

The remainder of the paper proceeds as follows. Section 2 presents a sticky-price model with labor market search and matching frictions. In this model, Section 3 examines equilibrium determinacy under inflation-forecast targeting policy. Section 4 provides a sensitivity analysis. Finally, Section 5 concludes.

\section{$2 \quad$ A sticky-price model with labor market search}

The model is an optimizing sticky-price model with labor market search and matching frictions in line with the recent studies presented before (See the Appendix for details of the model). The loglinearized equilibrium conditions are displayed in Panel A of Table 1. Eq. (T.1) is the Euler equation 
for optimal saving decisions, (T.2) describes the marginal utility of consumption, (T.3) is the resource constraint, (T.4) defines labor market tightness as the ratio of vacancies to job searchers, (T.5) is the law of motion of employment, (T.6) is the job creation condition that relates labor market tightness to real marginal cost, (T.7) is the New Keynesian Phillips curve, and (T.8) is interest rate policy.

The ensuing analysis uses a quarterly calibration of model parameters for the U.S. economy to illustrate conditions for determinacy. The baseline calibration is summarized in Panel B of Table 1. As in the monetary policy literature, the discount factor is set at $\beta=0.99$, the risk aversion at $\sigma=1$, the habit persistence at $h=0.8$, the substitution elasticity at $\epsilon=10$, and the probability of no price reoptimization at $\alpha=0.67$. Regarding the labor market parameters, the worker bargaining power of $\eta=0.5$ and the search elasticity of matches of $\xi=0.5$ are common values adopted in the labor market search literature. The flow value of unemployment of $b=0.7$ is an intermediate value in a wide range considered in the recent literature, as in line with Hall and Milgrom (2008). The job destruction rate and the steady-state unemployment rate are set respectively at $\rho=0.1$ and $U=1-n=0.06$, and these two parameters determine the steady-state job finding probability of $p=0.61 .^{2}$ The flow cost of vacancy posting of $\gamma=0.18$ is chosen to target the steady-state job filling rate at $q=0.7$.

\section{Indeterminacy under inflation-forecast targeting policy}

In the model presented above, this section examines implications of the labor market frictions for inflation-forecast targeting policy (i.e. $i=1$ in (T.8)) in terms of equilibrium determinacy.

First, strictly inflation-forecast targeting policy (i.e. $\phi_{U}=\phi_{R}=0$ in (T.8)) is considered in the absence of habit persistence in consumption preferences (i.e. $h=0$ ), in order to facilitate comparison with previous studies that consider a frictionless labor market. In that case, the system of log-linearized equilibrium conditions (T.1)-(T.8) can be reduced to a system of the form $E_{t}\left[\begin{array}{lll}\pi_{t+1} & n_{t+1} & n_{t}\end{array}\right]^{\prime}=A\left[\begin{array}{lll}\pi_{t} & n_{t} n_{t-1}\end{array}\right]^{\prime}$, where the coefficient matrix $A$ is given in the Appendix. In this system, $n_{t-1}$ is predetermined but $\pi_{t}$ and $n_{t}$ are not. Therefore, determinacy is generated if and only if the matrix $A$ has exactly one eigenvalue inside the unit circle and the other two outside the unit

\footnotetext{
${ }^{2}$ The steady-state job finding probability of 0.61 is smaller than some estimates for the U.S. economy. For instance, Shimer (2005) reports an average quarterly job finding rate of 0.83 . Section 4 considers calibrations of $\rho$ and $U$ that generate a larger steady-state job finding rate (including $p=0.83$ ) than their baseline calibration does.
} 
circle. The following proposition is thus obtained using Proposition C.2 of Woodford (2003).

Proposition 1 In the absence of habit persistence in consumption preferences (i.e. $h=0)$, strictly inflation-forecast targeting policy (i.e. $i=1, \phi_{U}=\phi_{R}=0$ in (T.8)) ensures determinacy of equilibrium if and only if either of the following two cases is satisfied.

Case I: (1)-(4) hold. Or (1), (2), and the strict inequality opposite to (3) hold.

$$
\begin{gathered}
\phi_{\pi}>1, \\
\left\{\left(1-\rho \frac{\gamma}{q}\right)[\rho+2 U(1-\rho)][\xi+\beta(1-\rho)(\xi-\eta p)]-2 \beta a_{1}(1-\rho)(1-\eta p)\right\}\left(\phi_{\pi}-1\right)<\frac{2(1+\beta) \xi a_{1}}{\kappa_{\theta}}, \\
{\left[\left(1-\rho \frac{\gamma}{q}\right)(\xi-\eta p)-\sigma \rho\left(1-\xi-\frac{\gamma}{q}\right)(1-\eta p)\right]\left(\phi_{\pi}-1\right)<\frac{\sigma \xi \rho}{\kappa_{\theta}(1-\rho)}\left(1-\xi-\frac{\gamma}{q}\right),} \\
a_{2}\left(\phi_{\pi}-1\right)^{2}+a_{3}\left(\phi_{\pi}-1\right)+a_{4}>0 \quad \text { or } \quad\left|a_{5}\left(\phi_{\pi}-1\right)+a_{6}\right|-\left|a_{7}\left(\phi_{\pi}-1\right)+a_{8}\right|>0,
\end{gathered}
$$

where $\kappa_{\theta}=\kappa \xi(\gamma / q)[\epsilon /(\epsilon-1)] /(1-\eta)$, and $a_{i}, i=1, \ldots, 8$ are given in the Appendix.

Case II: (4) and the three strict inequalities opposite to (1)-(3) hold. Or (3) and the two strict inequalities opposite to (1) and (2) hold.

Proof See the Appendix.

Under the baseline calibration except with $h=0,(1)-(4)$ are the relevant conditions for determinacy and show that the strictly inflation-forecast targeting policy guarantees determinacy for a very narrow interval of the inflation coefficient, $1<\phi_{\pi}<1.04$. The lower bound of this interval is the Taylor principle (1), and the upper bound is given by the first inequality of (4), which severely limits the size of the inflation coefficient ensuring determinacy. This is due to the vacancy channel of monetary policy illustrated in the Introduction. This channel leads a rise in the real interest rate to increase expected future inflation and therefore makes inflationary expectations self-fulfilling under the policy. This result is in stark contrast to Proposition 4 of Bullard and Mitra (2002) and Proposition 4.5 of Woodford (2003), which consider a frictionless labor market and show that the strictly inflation-forecast targeting policy ensures determinacy if and only if it satisfies the Taylor principle but its response to expected future inflation is not too strong (e.g. $1<\phi_{\pi}<25$ under our baseline calibration except with $h=0)$.

Turning next to the baseline calibration with consumption habit persistence (i.e. $h=0.8$ ), how does this affect the incidence of indeterminacy? As noted before, the vacancy channel of monetary 
policy induces indeterminacy under the strictly inflation-forecast targeting policy, because output supply recovers sluggishly relative to expected future consumption demand after a tightening of the policy. This suggests that indeterminacy might be less severe when habit persistence in consumption preferences is taken into account, since such persistence implies that consumption demand adjusts gradually to changes in the real interest rate so that employment could adjust despite the labor market frictions. However, under the baseline calibration of $h=0.8$, the interval of the inflation coefficient ensuring determinacy is only slightly wider, $1<\phi_{\pi}<1.06$. More generally, the upper left panel of Fig. 1 shows that the determinacy interval widens slightly as $h$ increases. Therefore, consumption habit persistence is not relevant for indeterminacy under the strictly inflation-forecast targeting policy.

A higher job destruction rate decreases the sluggishness of employment adjustment in the law of motion (T.5), and hence weakens the effect of the vacancy channel. The upper right panel of Fig. 1 shows that for the job destruction rate greater than the threshold value of $\rho=0.08$, the determinacy interval widens as $\rho$ increases. However, when the job destruction rate is smaller than this threshold value, only the policy that fails to meet the Taylor principle makes determinacy possible. In that case, firms adjust employment very sluggishly to changes in consumption demand, and thus the effect of the vacancy channel is stronger than that of the aggregate demand channel for any policy response to expected future inflation. Therefore, if the real interest rate declines in response to a rise in inflation expectations, the resulting decrease in expected future consumption demand combined with a persistent increase in employment lowers expected future inflation. This prevents the initial inflationary expectations from becoming self-fulfilling.

The bottom two panels of Fig. 1 investigate whether a policy that is flexibly inflation-forecast targeting or contains policy rate smoothing is more likely to ensure determinacy. These policies are motivated by empirical studies such as Clarida et al. $(1998,2000)$, who use them as a good description of actual monetary policy conducted in industrialized countries. ${ }^{3}$ With an active policy response to

\footnotetext{
${ }^{3}$ These studies focus on policy responses to output rather than unemployment, although Clarida et al. (2000) also estimate policy rules with the unemployment rate. However, in our model percent changes in output are reflected to a large extent in percentage point changes in the unemployment rate, because labor is the only production input. Therefore, policies that respond to output would have similar implications for determinacy as those that respond to unemployment.
} 
the inflation forecast, a sufficiently large policy response to the unemployment rate forecast or a sufficiently high degree of policy rate smoothing ensures determinacy. With typical values from estimated policy rules, e.g. $\phi_{U}=0.5$ and $\phi_{R}=0.8$ as in line with the estimates of Clarida et al. (2000) for the Volcker-Greenspan period, determinacy is guaranteed. This is because the feedback from the expected future unemployment rate or the past policy rate smoothens the change in the current policy rate in response to a shift in inflation expectations. This dampens the resulting change in the real interest rate and hence the change in consumption. Indeed, unemployment rises as a consequence of a rise in the real interest rate stemming from inflationary expectations and hence the negative policy response to the unemployment rate subdues such a rate rise. The results in the bottom panels of Fig. 1 provide an explanation for why the U.S. economy has not shown excessive volatility in recent decades in which Orphanides and Wieland (2008) indicate that U.S. monetary policy has been forecast-based. From a normative perspective, the results provide an argument in favor of the policies in place of the strictly inflation-forecast targeting policy.

\section{Sensitivity analysis}

This section conducts a sensitivity analysis of equilibrium determinacy regarding values of model parameters and the specification of interest rate policy. The results are summarized in Table 2.

\subsection{Forecast-based policy}

The first column with results shows how the interval of the inflation coefficient of strictly inflationforecast targeting policy that ensures determinacy changes with values of the model parameters. The strength of the recovery of expected future consumption in response to a rise in the real interest rate is determined by the degree of risk aversion $\sigma$ as well as that of habit persistence $h$ examined above. A lower value of the risk aversion means a higher elasticity of substitution of current with future consumption and thereby makes indeterminacy more severe. On the other hand, the sluggishness of employment adjustment is determined directly by the steady-state unemployment rate $U$ as well as the job destruction rate $\rho$ analyzed above. ${ }^{4}$ Using (T.4) to substitute for the labor market tightness

\footnotetext{
${ }^{4}$ The steady-state job finding rate in the cases of $\rho=0.15$ and $U=0.02$ respectively equals 0.7 and 0.83 .
} 
$\theta_{t}$ in the employment law of motion (T.5), it can be shown that a high value of $U$ implies that changes in current employment persist strongly into the future. Consequently, for the value of $U=0.1$, the Taylor principle fails to ensure determinacy, since the effect of the vacancy channel is stronger than that of the aggregate demand channel for any inflation coefficient $\phi_{\pi}$.

The job creation condition (T.6) relates labor market tightness to real marginal cost. Using (T.6) to substitute for the real marginal cost $z_{t}$ in the Phillips curve (T.7), the labor market tightness elasticity of inflation can be written as $\kappa_{\theta}=\kappa \xi(\gamma / q)[\epsilon /(\epsilon-1)] /(1-\eta)$. A larger value of this elasticity amplifies the impact of current labor market tightness on current inflation via the aggregate demand channel. But it also amplifies the impact of expected future labor market tightness on expected future inflation via the vacancy channel. Then, under an inflation-forecast targeting policy, an amplified shift in inflation expectations results in an amplified change in the real interest rate, which induces a strong expected adjustment of future consumption. Consequently, a larger labor market tightness elasticity of inflation strengthens the effect of the vacancy channel relative to the demand channel.

For instance, a smaller flow value of unemployment $(b)$ yields a larger steady-state match value $(\gamma / q)$ and hence increases the elasticity $\kappa_{\theta}$, and at the same time indeterminacy becomes more severe. ${ }^{5}$ Also, a lower value of worker bargaining power $\eta$, although it reduces the elasticity $\kappa_{\theta}$ directly, increases the steady-state match value $\gamma / q$, which on balance raises the elasticity $\kappa_{\theta}$ and makes indeterminacy more likely. ${ }^{6}$ A smaller value of the substitution elasticity $\epsilon$ increases the steady-state markup $\epsilon /(\epsilon-1)$, but reduces the steady-state match value $\gamma / q$ by more, and thus the elasticity $\kappa_{\theta}$ declines and indeterminacy is mitigated. ${ }^{7}$ Moreover, a smaller probability of no price reoptimization $(\alpha)$ increases the elasticity $\kappa_{\theta}$ via the relation $\kappa=(1-\alpha)(1-\alpha \beta) / \alpha$ and leads to more severe indeterminacy.

The search elasticity of matches, $\xi$, induces indeterminacy in two ways. First, like the lower job destruction rate $\rho$ and the higher steady-state unemployment rate $U$ illustrated above, a smaller value

\footnotetext{
${ }^{5}$ Likewise, Hagedorn and Manovskii (2008) stress that the flow value of unemployment is an important determinant of the productivity elasticity of labor market tightness in the Mortensen-Pissarides (1994) search and matching model.

${ }^{6}$ The high values of $b=0.76$ and $\eta=0.6$ in Table 2 satisfy the condition that the job finding probability and the vacancy filling probability lie within the unit interval, but parameter values higher than these would violate that condition.

${ }^{7}$ The steady-state match value $\gamma / q$ is invariant to the flow cost of vacancy posting, $\gamma$, and hence indeterminacy is invariant to $\gamma$.
} 
of $\xi$ increases the sluggishness of employment adjustment in the law of motion obtained by combining (T.4) and (T.5). This leads the small value of $\xi=0.2$ to narrow the determinacy interval of the inflation coefficient $\phi_{\pi}$. Second, a larger value of $\xi$ increases the labor market tightness elasticity of inflation, $\kappa_{\theta}$. Consequently, the high value of $\xi=0.7$ causes the Taylor principle to fail to ensure determinacy.

The next column illustrates the case of flexibly inflation-forecast targeting policy with interest rate smoothing, i.e. $i=1, \phi_{U}=0.5, \phi_{R}=0.8$ in (T.8). For parameter values that require active policy to ensure determinacy, the upper bound on the determinacy interval of the inflation coefficient $\phi_{\pi}$ increases (decreases) when these parameters weaken (strengthen) the relative effect of the vacancy channel to the aggregate demand channel. However, unlike the case of strictly inflation-forecast targeting policy, this interval is always wide enough to include realistic values of the inflation coefficient, e.g. Clarida et al. (2000)'s estimate of $\phi_{\pi}=2.15$. When the adjustment of employment relative to that of consumption is very sluggish, only a passive policy response to expected future inflation guarantees determinacy even if the policy is flexibly inflation-forecast targeting and contains policy rate smoothing.

Parameter values for which the Taylor principle fails to guarantee determinacy have been used in previous studies to calibrate their models to the U.S. economy. For instance, Merz (1995) sets the job destruction rate at $\rho=0.07$, which is within the range of values that require passive policy. The high unemployment rate of $U=0.1$ corresponds to Blanchard and Galí (2010)'s European calibration. However, some studies with U.S. calibrations adopt even larger values, reflecting the view that a share of the population that is out of the labor force also searches for jobs. For instance, Andolfatto (1996) chooses $n=0.57$, implying $U=0.43$, based on the average U.S. employment-population ratio. The high search elasticity of matches of $\xi=0.7$ and the small flow value of unemployment of $b=0.4$ are in line with the values used by Shimer $(2005){ }^{8}$

\footnotetext{
${ }^{8}$ Calibrations with a low job destruction rate and a high unemployment rate may feature European labor markets well, suggesting that the Taylor principle is more likely to fail to guarantee determinacy in those economies. Likewise, as Shimer (2005) emphasizes, the search and matching model under his calibration is not able to generate large labor market flows as observed in the U.S. labor market.
} 


\subsection{Outcome-based policy}

The last two columns of Table 2 present the results of determinacy under outcome-based policy (i.e. $i=0$ in $($ T.8)). The interval of the inflation coefficient that ensures determinacy is always wide enough to include its realistic values as long as the Taylor principle is a necessary condition for determinacy. Intuitively, an active policy response to inflation increases the real interest rate, but such inflation is dampened by the decline of real marginal cost that results from the rise in the real interest rate. Consequently, the policy rate rise and hence the real interest rate rise are subdued, and thus determinacy is guaranteed.

In the absence of consumption habit persistence, determinacy is ensured as long as the Taylor principle is satisfied, i.e. $\phi_{\pi}>1$, in line with Bullard and Mitra (2002) and Woodford (2003) who consider the case of a frictionless labor market. With the habit persistence and high risk aversion, the determinacy interval narrows, which may look inconsistent with the intuition, but there are actually multiple determinacy intervals; e.g. under the baseline calibration, inflation coefficients in the interval $[6.95,27.62)$ induce indeterminacy whereas larger coefficients guarantee determinacy. For the baseline calibration of the habit persistence and the risk aversion, varying other parameter values affects the upper bound on the determinacy interval in the same direction as it does under the forecast-based policy and thus in line with the changing effect of the vacancy channel, although multiple determinacy intervals exist. For parameter calibrations that induce a high sluggishness of employment adjustment relative to that of consumption changes, a passive policy response to inflation ensures determinacy, regardless of whether the policy is strictly or flexibly inflation targeting or contains policy rate smoothing.

\section{Conclusion}

Labor market search and matching frictions cause sluggish adjustment of employment and hence of output supply to changes in consumption demand. Consequently, a rise in the real interest rate increases expected future real marginal cost and hence expected future inflation. Therefore, indeterminacy is likely if interest rate policy is strictly inflation-forecast targeting and meets the Taylor principle. If the sluggishness of the adjustment of employment relative to that of consumption is 
high, a passive policy response to inflation ensures determinacy, regardless of whether the policy is forecast-based or outcome-based or whether it is strictly or flexibly inflation targeting or contains policy rate smoothing. 


\section{References}

[1] Blanchard, O.J., Galí, J., 2010. Labor markets and monetary policy: a new Keynesian model with unemployment. American Economic Journal: Macroeconomics 2, 1-30.

[2] Bullard, J.B., Mitra, K., 2002. Learning about monetary policy rules. Journal of Monetary Economics 49, 1105-1129.

[3] Clarida, R., Galí, J., Gertler, M., 1998. Monetary policy rules in practice: Some international evidence. European Economic Review 42, 1033-1067.

[4] Clarida, R., Galí, J., Gertler, M., 2000. Monetary policy rules and macroeconomic stability: Evidence and some theory. Quarterly Journal of Economics 115, 147-180.

[5] Faia, E., 2009. Ramsey monetary policy with labor market frictions. Journal of Monetary Economics 56, 570-581.

[6] Hagedorn, M., Manovskii, I., 2008. The cyclical behavior of equilibrium unemployment and vacancies revisited. American Economic Review 98, 1692-1706.

[7] Hall, R.E., Milgrom, P.R., 2008. The limited influence of unemployment on the wage bargain. American Economic Review 98, 1653-1674.

[8] Krause, M.U., Lubik, T.A., 2007. The (ir)relevance of real wage rigidity in the new Keynesian model with search frictions. Journal of Monetary Economics 54, 706-727.

[9] Kurozumi, T., Van Zandweghe, W., 2008. Labor market search and interest rate policy. Research Working Paper 08-03, Federal Reserve Bank of Kansas City.

[10] Merz, M., 1995. Search in the labor market and the real business cycle. Journal of Monetary Economics 36, 269-300.

[11] Mortensen, D.T., Pissarides, C.A., 1994. Job creation and job destruction in the theory of unemployment. Review of Economic Studies 61, 397-415. 
[12] Orphanides, A., Wieland, V., 2008. Economic projections and rules of thumb for monetary policy. Federal Reserve Bank of St. Louis Review 90, 307-324.

[13] Rannenberg, A., 2009. The Taylor principle and (in-)determinacy in a new Keynesian model with hiring frictions and skill loss. CDMA working paper 09/09, University of St Andrews.

[14] Ravenna, F., Walsh, C.E., 2010. Welfare-based optimal monetary policy with unemployment and sticky prices: a linear-quadratic framework. American Economic Journal: Macroeconomics, forthcoming.

[15] Shimer, R., 2005. The cyclical behavior of equilibrium unemployment and vacancies. American Economic Review 95, 25-49.

[16] Sveen, T., Weinke, L., 2009. Inflation and labor market dynamics revisited. Journal of Monetary Economics 56, 1096-1100.

[17] Tesfaselassie, M.F., Schaling, E., 2009. On determinacy and learnability in a new Keynesian model with unemployment. Kiel Working Paper 1506, Kiel Institute for the World Economy.

[18] Thomas, C., 2008. Search and matching frictions and optimal monetary policy. Journal of Monetary Economics 55, 936-956.

[19] Trigari, A., 2009. Equilibrium unemployment, job flows and inflation dynamics. Journal of Money, Credit and Banking 41, 1-33.

[20] Van Zandweghe, W., 2010. On-the-job search, sticky prices, and persistence. Journal of Economic Dynamics and Control 34, 437-455.

[21] Walsh, C.E., 2005. Labor market search, sticky prices, and interest rate policies. Review of Economic Dynamics 8, 829-849.

[22] Woodford, M., 2003. Interest and Prices: Foundations of a Theory of Monetary Policy. Princeton University Press, Princeton, NJ. 
Table 1: Sticky-price model with labor market search and matching frictions.

$$
\begin{aligned}
& \text { A. System of log-linearized equilibrium conditions } \\
& \begin{aligned}
& \lambda_{t}=E_{t} \lambda_{t+1}+R_{t}-E_{t} \pi_{t+1} \\
& \lambda_{t}=-\frac{\sigma}{(1-h)(1-\beta h)}\left[c_{t}-h c_{t-1}-\beta h\left(E_{t} c_{t+1}-h c_{t}\right)\right] \\
& n_{t}=(1-\rho \gamma / q) c_{t}+\rho \gamma / q v_{t} \\
& \theta_{t}= v_{t}+\frac{(1-\rho)(1-U)}{1-(1-\rho)(1-U)} n_{t-1} \\
& n_{t}=(1-\rho) n_{t-1}+\rho\left(v_{t}-\xi \theta_{t}\right) \\
& \xi \theta_{t}= \frac{(\epsilon-1)(1-\eta)}{\epsilon \gamma / q} z_{t}+\beta(1-\rho)\left[(\xi-\eta p) E_{t} \theta_{t+1}-(1-\eta p)\left(R_{t}-E_{t} \pi_{t+1}\right)\right] \\
& \pi_{t}=\beta E_{t} \pi_{t+1}+\kappa z_{t} \\
& R_{t}=\phi_{R} R_{t-1}+\left(1-\phi_{R}\right)\left[\phi_{\pi} E_{t} \pi_{t+i}+\phi_{U}(1-U) E_{t} n_{t+i}\right], i=0,1
\end{aligned}
\end{aligned}
$$

\begin{tabular}{lll} 
B. & Baseline calibration & \\
$\beta$ & subjective discount factor & 0.99 \\
$\sigma$ & relative risk aversion & 1 \\
$h$ & internal habit persistence in consumption preferences & 0.8 \\
$\epsilon$ & elasticity of substitution between retail goods & 10 \\
$\alpha$ & probability of no price reoptimization & 0.67 \\
$\eta$ & worker bargaining power & 0.5 \\
$\xi$ & search elasticity of matches & 0.5 \\
$b$ & flow value of unemployment & 0.7 \\
$\rho$ & job destruction rate & 0.1 \\
$U$ & steady-state unemployment rate & 0.06 \\
$\gamma$ & flow cost of vacancy posting & 0.18 \\
\hline
\end{tabular}

Notes: $\pi_{t}$ is inflation, $R_{t}$ is the nominal interest rate, $z_{t}$ is real marginal cost, $n_{t}$ is employment, $v_{t}$ is vacancies, $\theta_{t}$ is labor market tightness, $c_{t}$ is consumption, and $\lambda_{t}$ is the marginal utility of consumption. $\kappa=(1-\alpha)(1-\alpha \beta) / \alpha$ is the real marginal cost elasticity of inflation, $p$ is the steady-state job finding rate, and $q$ is the steady-state vacancy filling rate. The job destruction rate $(\rho)$ and the steady-state unemployment rate $(U)$ determine $p$, which is 0.61 under the baseline calibration. The flow cost of vacancy posting $(\gamma)$ is chosen to set $q$ at a target value, which is 0.7 under the baseline calibration. 
Table 2: Interval of the inflation coefficient $\phi_{\pi}$ of policy ensuring determinacy.

\begin{tabular}{lllll}
\hline Policy & \multicolumn{2}{l}{ Forecast-based } & \multicolumn{2}{l}{ Outcome-based } \\
$\left\{\phi_{U}, \phi_{R}\right\}$ & $\{0,0\}$ & $\{0.5,0.8\}$ & $\{0,0\}$ & $\{0.5,0.8\}$ \\
\hline Baseline & $(1,1.06)$ & $(0.99,34.67)$ & $(1,6.95)^{\star}$ & $(0.99, \bar{\phi})$ \\
$h=0$ & $(1,1.04)$ & $(0.99,11.56)$ & $(1, \bar{\phi})$ & $(0.99, \bar{\phi})$ \\
$\sigma=0.2$ & $(1,1.02)$ & $(0.99, \bar{\phi})$ & $(1, \bar{\phi})$ & $(0.99, \bar{\phi})$ \\
$\sigma=5$ & $(1,1.12)$ & $(0.99,15.15)$ & $(1,2.68)^{\star}$ & $(0.99, \bar{\phi})$ \\
$\rho=0.07$ & $(0,1)$ & $(0,0.99)$ & $(0,1)^{\star}$ & $(0,0.99)$ \\
$\rho=0.15$ & $(1,1.11)$ & $(0.98, \bar{\phi})$ & $(1,8.89)^{\star}$ & $(0.98, \bar{\phi})$ \\
$U=0.02$ & $(1,1.10)$ & $(0.99, \bar{\phi})$ & $(1,19.79)^{\star}$ & $(0.99, \bar{\phi})$ \\
$U=0.1$ & $(0,1)$ & $(0,0.99)$ & $(0,1)^{\star}$ & $(0,0.99)^{\star}$ \\
$b=0.4$ & $(0,1)$ & $(0,1)$ & $(0,1)^{\star}$ & $(0,1)$ \\
$b=0.76$ & $(1,1.13)$ & $(0.98, \bar{\phi})$ & $(1,10.72)^{\star}$ & $(0.98, \bar{\phi})$ \\
$\eta=0.1$ & $(0,1)$ & $(0,0.99)$ & $(0,1)^{\star}$ & $(0,0.99)$ \\
$\eta=0.6$ & $(1,1.06)$ & $(0.99, \bar{\phi})$ & $(1,8.65)^{\star}$ & $(0.99, \bar{\phi})$ \\
$\epsilon=7$ & $(1,1.10)$ & $(0.99, \bar{\phi})$ & $(1,9.07)^{\star}$ & $(0.99, \bar{\phi})$ \\
$\alpha=0.5$ & $(1,1.02)$ & $(1,15.96)$ & $(1,3.98)^{\star}$ & $(1, \bar{\phi})$ \\
$\alpha=0.8$ & $(1,1.20)$ & $(0.96, \bar{\phi})$ & $(1,15.16)^{\star}$ & $(0.96, \bar{\phi})$ \\
$\xi=0.2$ & $(1,1.04)$ & $(0.98,15.29)$ & $(1,2.36)$ & $(0.98, \bar{\phi})$ \\
$\xi=0.7$ & $(0,1)$ & $(0,0.99)$ & $(0,1)^{\star}$ & $(0,0.99)$ \\
\hline
\end{tabular}

Notes: $\bar{\phi}$ denotes the maximum value of $\phi_{\pi}$ considered in this paper and it is set to 40 . A star $\left(^{\star}\right)$ indicates that there is at least one other disjoint interval of more aggressive policy responses ensuring determinacy. 
Figure 1: Regions of forecast-based policy responses ensuring determinacy.
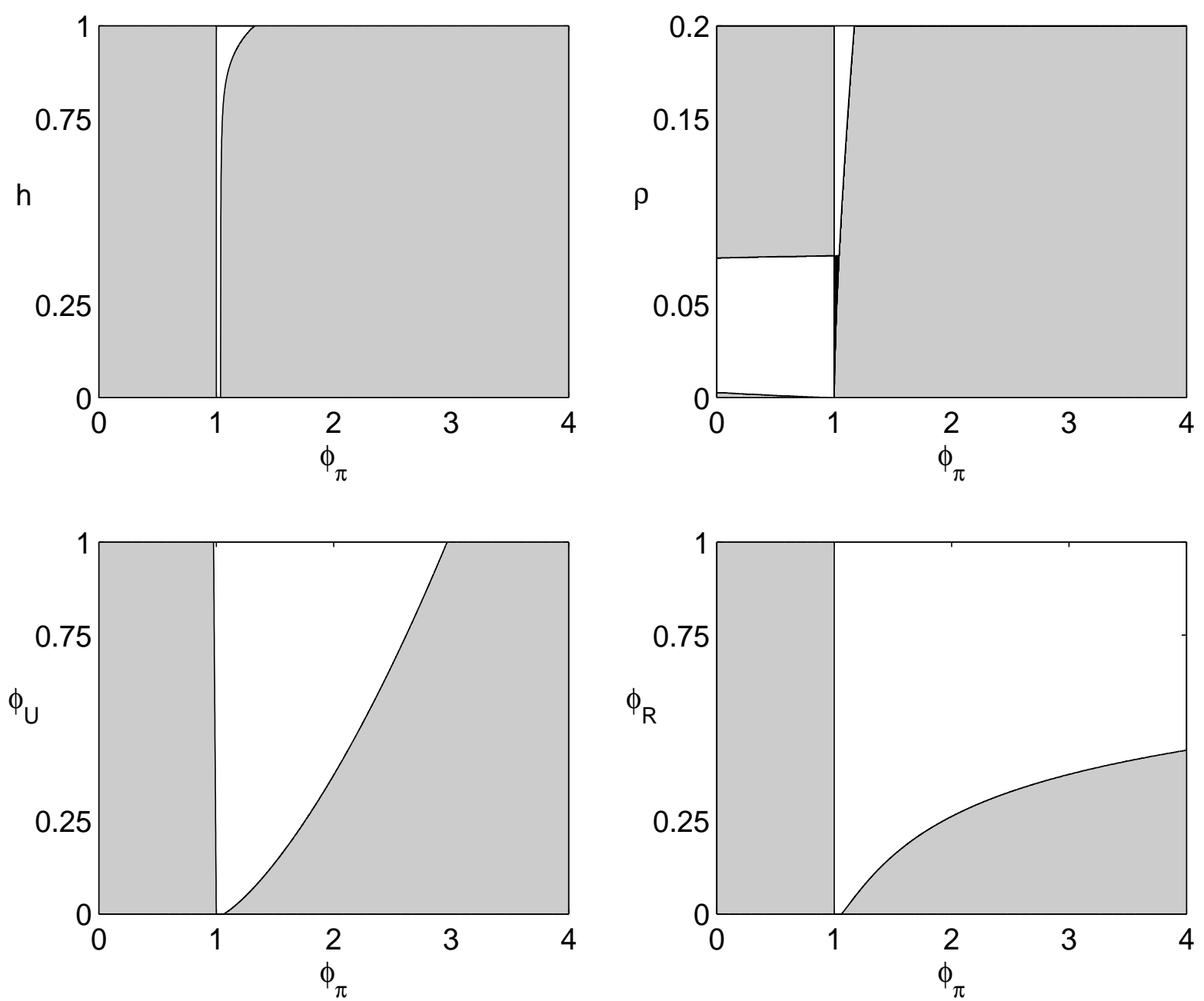

Notes: Each panel uses the baseline calibration with $\phi_{U}=\phi_{R}=0$, except for the parameter of the vertical axis. White, gray, and black areas indicate respectively regions of determinate, indeterminate, and explosive equilibrium. 


\section{A Appendix}

This appendix presents details of our sticky-price model with labor market search and matching frictions. It also contains the proof of Proposition 1, which provides necessary and sufficient conditions for determinacy of equilibrium when interest rate policy is strictly inflation-forecast targeting in the absence of habit persistence in consumption preferences.

\section{A.1 A sticky-price model with labor market search}

The model is an optimizing sticky-price model with labor market search and matching frictions. This model is in line with recent business cycle studies, such as Walsh (2005), Krause and Lubik (2007), Sveen and Weinke (2009), Trigari (2009), and Van Zandweghe (2010), and recent monetary policy studies, such as Thomas (2008), Faia (2009), and Ravenna and Walsh (2010).

The economy is inhabited by four types of agents. First, the representative household consists of a continuum of members. Some members are employed and others search for jobs, but all members provide each other with insurance against unemployment risk by making joint consumption and saving decisions. Second, the representative wholesale firm hires workers in the matching market, and uses a linear technology to produce homogeneous goods. Third, retail firms transform wholesale goods into differentiated goods and set prices on a staggered basis as in Calvo (1983). Finally, the monetary authority sets its policy rate according to a Taylor (1993) style rule. A sunspot shock to inflation expectations is assumed to be the only source of aggregate uncertainty in the economy.

\section{A.1.1 Labor market}

The labor market is characterized by search and matching frictions along the lines of Mortensen and Pissarides (1994). Unemployed workers search for jobs, and firms pay a flow cost $P_{t} \gamma$ to maintain a job opening in period $t$. At the beginning of the period, a proportion $\rho \in(0,1)$ of existing matches $n_{t-1}$ is exogenously destroyed before matching starts. Newly matched workers $m_{t}$ become productive instantaneously, and thus the law of motion of employment is

$$
n_{t}=(1-\rho) n_{t-1}+m_{t}
$$


The matching friction faced by workers and firms is represented by a constant returns to scale matching function that determines the number of new matches between job searchers and vacancies as

$$
m_{t}=\psi u_{t}^{\xi} v_{t}^{1-\xi}
$$

where $\psi>0, \xi \in(0,1), v_{t}$ denotes the number of vacancies, and $u_{t}$ is the number of searching workers. With the labor force normalized to one, the latter is given by

$$
u_{t}=1-(1-\rho) n_{t-1},
$$

while the unemployment rate is defined as

$$
U_{t}=1-n_{t}
$$

The job finding probability $p_{t}$ and the vacancy filling probability $q_{t}$ are given by

$$
\begin{aligned}
p_{t} & \equiv \frac{m_{t}}{u_{t}}=\psi \theta_{t}^{1-\xi}, \\
q_{t} & \equiv \frac{m_{t}}{v_{t}}=\psi \theta_{t}^{-\xi},
\end{aligned}
$$

where the ratio of vacancies to searchers

$$
\theta_{t}=\frac{v_{t}}{u_{t}}
$$

measures the labor market tightness. Thus, when the labor market is tight, a worker is more likely to find a job, and a firm is less likely to fill a vacancy.

\section{A.1.2 Representative household}

The representative household consists of a continuum of household members. To avoid distributional issues, it is assumed as in Andolfatto (1996) and Merz (1995) that employed and unemployed household members pool consumption. Thus, the presence of a representative household can be considered. This household purchases consumption goods $c_{t}$, supplies one unit of labor inelastically, and holds nominal one-period bonds $B_{t}$ that earn the gross nominal interest rate $R_{t}$ in the subsequent period. The household chooses consumption and bond holdings so as to maximize expected lifetime utility

$$
\max E_{0} \sum_{t=0}^{\infty} \beta^{t} \frac{\left(c_{t}-h c_{t-1}\right)^{1-\sigma}}{1-\sigma}
$$


subject to the budget constraint

$$
P_{t} c_{t}+B_{t}=P_{t}\left[w_{t} n_{t}+b\left(1-n_{t}\right)\right]+D_{t}+B_{t-1} R_{t-1}
$$

Here, $\beta \in(0,1)$ is the subjective discount factor, $\sigma>0$ measures relative risk aversion, and $h$ is the degree of (internal) habit persistence in consumption preferences. Family income consists of wage income $P_{t} w_{t} n_{t}$ from employment, unemployment income $P_{t} b\left(1-n_{t}\right)$, and other income $D_{t}$.

The disutility from employment is normalized to zero. Consumption $c_{t}=\left[\int_{0}^{1} c_{t}(j)^{(\epsilon-1) / \epsilon} d j\right]^{\epsilon /(\epsilon-1)}$ is a composite of differentiated goods produced by retail firms, with the substitution elasticity $\epsilon>1$. Thus, cost-minimizing demand for good $j$ is given by $c_{t}(j)=\left(P_{t}(j) / P_{t}\right)^{-\epsilon} c_{t}$, where the aggregate price index satisfies

$$
P_{t}=\left(\int_{0}^{1} P_{t}(j)^{\epsilon-1} d j\right)^{\frac{1}{\epsilon-1}} .
$$

The optimality conditions for consumption and bond holdings are given by

$$
\begin{aligned}
\lambda_{t} & =\left(c_{t}-h c_{t-1}\right)^{-\sigma}-\beta h E_{t}\left(c_{t+1}-h c_{t}\right)^{-\sigma} \\
\lambda_{t} & =\beta E_{t} \lambda_{t+1} \frac{R_{t}}{\pi_{t+1}}
\end{aligned}
$$

where $\lambda_{t}$ is the marginal utility of consumption and $\pi_{t}=P_{t} / P_{t-1}$ is the gross inflation rate. Taking account of the labor market flows gives rise to the following asset value of employment

$$
W_{t}=w_{t}-b+\beta E_{t} \frac{\lambda_{t+1}}{\lambda_{t}}(1-\rho)\left(1-p_{t+1}\right) W_{t+1}
$$

The household's marginal value of a family member matched with a job equals the sum of the premium of the real wage over the unemployment benefit and the discounted expected future value. The latter is discounted by the time-varying discount factor that values future consumption in present terms and by the probability that the job is destroyed and no new job is found.

\section{A.1.3 Representative wholesale firm}

The representative wholesale firm uses a production technology that is linear in labor, $y_{t}=n_{t}$. This firm chooses employment $n_{t}$ and vacancies $v_{t}$ so as to maximize profits by selling its product at a relative price $z_{t}$ to retail firms in a perfectly competitive market. Thus, the firm solves the problem

$$
\max E_{0} \sum_{t=0}^{\infty} \beta^{t} \frac{\lambda_{t}}{\lambda_{0}}\left[\left(z_{t}-w_{t}\right) n_{t}-\gamma v_{t}\right]
$$


subject to (A.1) and (A.6). The conditions for profit maximization include

$$
\begin{aligned}
J_{t} & =z_{t}-w_{t}+\beta(1-\rho) E_{t} \frac{\lambda_{t+1}}{\lambda_{t}} J_{t+1}, \\
\frac{\gamma}{q_{t}} & =J_{t},
\end{aligned}
$$

where the Lagrange multiplier on the employment law of motion (A.1), $J_{t}$, denotes the firm's asset value of a filled job, which consists of the current return plus the discounted expected future value. Profit maximization requires this value to be equal to the average cost of filling a job opening. The average cost is the flow cost of posting a vacancy times the number of vacancies posted in order to fill one job, which is the inverse of the vacancy filling probability.

The costly job creation gives rise to a surplus from a match, $S_{t}=J_{t}+W_{t}$, which is split between the matched worker and firm through Nash bargaining. The real wage is therefore set in order to provide the worker and the firm with a share of the match surplus $W_{t}=\eta S_{t}$ and $J_{t}=(1-\eta) S_{t}$, respectively, where $\eta \in(0,1)$ denotes the worker's relative bargaining power. The resulting real wage equation is

$$
w_{t}=\eta\left(z_{t}+\beta(1-\rho) E_{t} \frac{\lambda_{t+1}}{\lambda_{t}} p_{t+1} \frac{\gamma}{q_{t+1}}\right)+(1-\eta) b .
$$

A job entails compensation for a fraction $\eta$ of the revenue and the expected saving of hiring costs that the match generates, in addition to a fraction $1-\eta$ of the forgone unemployment income.

\section{A.1.4 Retail firms}

There is a continuum of retail firms $j \in[0,1]$, each of which produces one unit of differentiated good $j$ from one unit of wholesale goods and sells a quantity $Y_{t}(j)$ of good $j$ to households in a monopolistically competitive market. Cost minimization implies that each retail firm's real marginal cost is equal to the wholesale goods' real price $z_{t}$. Then, facing households' demand $Y_{t}(j)=c_{t}(j)=\left(P_{t}(j) / P_{t}\right)^{-\epsilon} c_{t}$, each retail firm chooses its profit-maximizing price subject to Calvo (1983) and Yun (1996) style price stickiness. That is, each period a fraction $\alpha \in[0,1)$ of retail firms does not reoptimize price and instead adjusts it for steady-state gross inflation $\pi$, while the remaining fraction $1-\alpha$ of firms faces the problem

$$
\max _{P_{t}(j)} E_{t} \sum_{k=0}^{\infty}(\alpha \beta)^{k} \frac{\lambda_{t+k}}{\lambda_{t}}\left(\frac{P_{t}(j) \pi^{k}}{P_{t+k}}-z_{t+k}\right)\left(\frac{P_{t}(j) \pi^{k}}{P_{t+k}}\right)^{-\epsilon} c_{t+k}
$$


The optimality condition for price setting is

$$
P_{t}(j)=\frac{\epsilon}{\epsilon-1} \frac{E_{t} \sum_{k=0}^{\infty}\left(\alpha \beta \pi^{-\epsilon}\right)^{k} \lambda_{t+k} P_{t+k}^{\epsilon} c_{t+k} z_{t+k}}{E_{t} \sum_{k=0}^{\infty}\left(\alpha \beta \pi^{1-\epsilon}\right)^{k} \lambda_{t+k} P_{t+k}^{\epsilon-1} c_{t+k}} .
$$

If prices are perfectly flexible (i.e. $\alpha=0),\left(\right.$ A.15) reduces to $P_{t}(j)=[\epsilon /(\epsilon-1)] P_{t} z_{t}$, which shows that $1 / z=\epsilon /(\epsilon-1)$ is the steady-state markup of each retail firm's price over its marginal cost. In the presence of price stickiness, the firm's actual markup differs from, but tends toward, the steady-state markup.

\section{A.1.5 Monetary authority}

The monetary authority conducts inflation targeting policy that adjusts the policy rate in response to either the present or expected future inflation and unemployment rates and contains policy rate smoothing

$$
R_{t}=\left(R_{t-1}\right)^{\phi_{R}}\left[R\left(\frac{E_{t} \pi_{t+i}}{\pi}\right)^{\phi_{\pi}}\left(\frac{1-E_{t} U_{t+i}}{1-U}\right)^{\phi_{U}}\right]^{1-\phi_{R}}, \quad i=0,1,
$$

where $R$ is the steady-state nominal interest rate, $\phi_{R} \in[0,1)$ is the degree of policy rate smoothing, and $\phi_{\pi}, \phi_{U}$ are non-negative policy coefficients on inflation and unemployment rates. These policy specifications are referred to as, respectively, outcome-based if $i=0$ and forecast-based if $i=1$.

\section{A.1.6 Log-linear approximation and calibration}

A rational expectations equilibrium (REE) is a set of processes for all the endogenous variables satisfying (A.1) - (A.16), the aggregate resource constraint $y_{t}=Y_{t}+\gamma v_{t}$, and the market clearing condition $Y_{t}(j)=c_{t}(j)$ for each retail good $j \in[0,1]$, which implies $Y_{t}=\Delta_{t} c_{t}$, where $\Delta_{t} \equiv \int_{0}^{1}\left(P_{t}(j) / P_{t}\right)^{-\epsilon} d j$ measures relative price dispersion across retail goods. Log-linearizing these equilibrium conditions around the steady state and rearranging the resulting equations yields Eqs. (T.1)-(T.8), where $\kappa \equiv(1-\alpha)(1-\alpha \beta) / \alpha>0$ is the real marginal cost elasticity of inflation, and the hat on a variable denotes its percentage deviation from the steady-state value. These equations are given in Panel A of Table 1 in the paper. In this system the unemployment rate and the number of searching workers 
have been substituted by

$$
\begin{aligned}
U_{t} & =U-(1-U) \hat{n}_{t}, \\
\hat{u}_{t} & =-\frac{(1-\rho)(1-U)}{1-(1-\rho)(1-U)} \hat{n}_{t-1} .
\end{aligned}
$$

Panel B of Table 1 in the paper contains the baseline calibration of model parameters and the steadystate unemployment rate. The steady-state job finding rate $p=m / u$ is obtained from the steadystate conditions of (A.1) and (A.4), which determine the steady-state number of new matches and job searchers as

$$
\begin{aligned}
m & =\rho(1-U), \\
u & =1-(1-\rho)(1-U) .
\end{aligned}
$$

The steady-state vacancy filling rate $q$ is obtained from the steady-state conditions of (A.12) and (A.14) as

$$
q=\gamma \frac{1-\beta(1-\rho)(1-\eta p)}{(1-\eta)(z-b)}
$$

\section{A.2 Indeterminacy under inflation-forecast targeting policy}

This section studies determinacy conditions when interest rate policy is strictly inflation-forecast targeting (i.e. $i=1, \phi_{U}=\phi_{R}=0$ in (T.8)) in the absence of habit persistence in consumption preferences (i.e. $h=0)$. The system of log-linearized equilibrium conditions (T.1)-(T.8) can then be reduced to a system of the form

$$
E_{t}\left[\hat{\pi}_{t+1} \hat{n}_{t+1} \hat{n}_{t}\right]^{\prime}=A\left[\hat{\pi}_{t} \hat{n}_{t} \hat{n}_{t-1}\right]^{\prime}
$$

where the coefficient matrix $A$ is given by

$$
A=\left[\begin{array}{ccc}
A_{11} / B & A_{12} / B & A_{13} / B \\
\alpha_{1}\left(A_{11} / B\right)\left(\phi_{\pi}-1\right) & 1-\alpha_{2}+\alpha_{1}\left(A_{12} / B\right)\left(\phi_{\pi}-1\right) & \alpha_{2}+\alpha_{1}\left(A_{13} / B\right)\left(\phi_{\pi}-1\right) \\
0 & 1 & 0
\end{array}\right]
$$


where

$$
\begin{aligned}
A_{11} & =\frac{\rho(1-\xi)(1-\eta)(\epsilon-1)}{\frac{\gamma}{q} \epsilon \beta}, \quad A_{12}=\frac{\kappa}{\beta}\left[\beta(1-\rho)(\xi-\eta p)\left(1-\alpha_{2}-p \frac{1-\rho}{\rho} \frac{U}{1-U}\right)-\xi\right] \\
A_{13} & =\frac{\kappa}{\beta}\left[\beta(1-\rho)(\xi-\eta p) \alpha_{2}+\xi p \frac{1-\rho}{\rho} \frac{U}{1-U}\right], \quad B=\beta A_{11}+\alpha_{3}\left(\phi_{\pi}-1\right) \\
\alpha_{1} & =\sigma^{-1} \frac{(1-\xi)\left(1-\rho \frac{\gamma}{q}\right)}{1-\xi-\frac{\gamma}{q}}, \quad \alpha_{2}=\frac{\rho(1-\xi)+U[1-\rho(1-\xi)]}{\rho+U(1-\rho)} \frac{(1-\rho) \frac{\gamma}{q}}{1-\xi-\frac{\gamma}{q}} \\
\alpha_{3} & =\kappa(1-\rho)\left[\rho(1-\xi)(1-\eta p)-\alpha_{1}(\xi-\eta p)\right] .
\end{aligned}
$$

In this system, $\hat{n}_{t-1}$ is predetermined but $\hat{\pi}_{t}$ and $\hat{n}_{t}$ are not. Therefore, determinacy of equilibrium is generated if and only if the coefficient matrix $A$ has exactly one eigenvalue inside the unit circle and the other two outside the unit circle. ${ }^{9}$ We thus obtain the following proposition using Proposition C.2 of Woodford (2003).

Proposition 2 In the absence of habit persistence in consumption preferences (i.e. $h=0)$, strictly inflation-forecast targeting policy (i.e. $i=1, \phi_{U}=\phi_{R}=0$ in (T.8)) ensures determinacy of equilibrium if and only if either of the following two cases is satisfied.

Case I: (A.19)-(A.22) hold. Or (A.19), (A.20), and the strict inequality opposite to (A.21) hold.

$$
\begin{gathered}
\phi_{\pi}>1 \\
\left\{\left(1-\rho \frac{\gamma}{q}\right)[\rho+2 U(1-\rho)][\xi+\beta(1-\rho)(\xi-\eta p)]-2 \beta a_{1}(1-\rho)(1-\eta p)\right\}\left(\phi_{\pi}-1\right)<\frac{2(1+\beta) \xi a_{1}}{\kappa_{\theta}} \\
{\left[\left(1-\rho \frac{\gamma}{q}\right)(\xi-\eta p)-\sigma \rho\left(1-\xi-\frac{\gamma}{q}\right)(1-\eta p)\right]\left(\phi_{\pi}-1\right)<\frac{\sigma \xi \rho}{\kappa_{\theta}(1-\rho)}\left(1-\xi-\frac{\gamma}{q}\right)} \\
a_{2}\left(\phi_{\pi}-1\right)^{2}+a_{3}\left(\phi_{\pi}-1\right)+a_{4}>0 \text { or }\left|a_{5}\left(\phi_{\pi}-1\right)+a_{6}\right|-\left|a_{7}\left(\phi_{\pi}-1\right)+a_{8}\right|>0
\end{gathered}
$$

where $\kappa_{\theta}=\frac{\kappa \xi \epsilon \gamma / q}{(\epsilon-1)(1-\eta)}, a_{1}=\sigma \rho\left\{\left(1-\xi-\frac{\gamma}{q}\right)[U+\rho(1-U)]-\frac{\gamma}{q}(1-\rho)[U+\rho(1-\xi)(1-U)]\right\}$, and $a_{i}, i=2, \ldots, 8$, are given in the Proof.

Case II: (A.22) and the three strict inequalities opposite to (A.19)-(A.21) hold. Or (A.21) and the two strict inequalities opposite to (A.19) and (A.20) hold.

Proof For the system's coefficient matrix $A$, it can be shown that its three eigenvalues are the solutions to the cubic equation

$$
\mu^{3}+b_{1} \mu^{2}+b_{2} \mu+b_{3}=0
$$

\footnotetext{
${ }^{9}$ To be precise, this condition is sufficient for determinacy but only generically necessary. Throughout the paper, consideration of non-generic boundary cases is omitted.
} 
where $b_{1}=\alpha_{2}-1-A_{11} / B-\alpha_{1}\left(A_{12} / B\right)\left(\phi_{\pi}-1\right), b_{2}=A_{11} / B-\alpha_{2}\left(1+A_{11} / B\right)-\alpha_{1}\left(A_{13} / B\right)\left(\phi_{\pi}-1\right)$, and $b_{3}=\alpha_{2} A_{11} / B$. Because determinacy of equilibrium obtains if and only if the coefficient matrix $A$ has exactly one eigenvalue inside the unit circle and the other two outside the unit circle, it follows that the necessary and sufficient condition for determinacy is that exactly one solution to the cubic equation is inside the unit circle and the other two are outside the unit circle. By Proposition C.2 of Woodford (2003), this is the case if and only if either of the following two cases is satisfied.

$$
\begin{aligned}
& \text { (Case 1) } 1+b_{1}+b_{2}+b_{3}<0,-1+b_{1}-b_{2}+b_{3}>0 \text {. } \\
& \left(\text { Case 2) } 1+b_{1}+b_{2}+b_{3}>0,-1+b_{1}-b_{2}+b_{3}<0, b_{3}\left(b_{3}-b_{1}\right)+b_{2}-1>0 \text { or }\left|b_{1}\right|>3\right. \text {. }
\end{aligned}
$$

The condition $b_{3}\left(b_{3}-b_{1}\right)+b_{2}-1>0$ can be written as $a_{2}\left(\phi_{\pi}-1\right)^{2}+a_{3}\left(\phi_{\pi}-1\right)+a_{4}>0$, where $a_{2}=-\alpha_{3}\left[\left(1+\alpha_{2}\right) \alpha_{3}+\alpha_{1} A_{13}\right], a_{3}=\left[\left(1+\alpha_{2}\right)\left(1-2 \beta-\alpha_{2}\right) \alpha_{3}+\alpha_{1}\left(\alpha_{2} A_{12}-\beta A_{13}\right)\right] A_{11}$, and $a_{4}=$ $\left(1+\alpha_{2}\right)\left(\alpha_{2}+\beta\right)(1-\beta) A_{11}^{2}$. The condition $\left|b_{1}\right|>3$ can be written as $\left|a_{5}\left(\phi_{\pi}-1\right)+a_{6}\right|-\left|a_{7}\left(\phi_{\pi}-1\right)+a_{8}\right|>0$, where $a_{5}=-\left[\left(1-\alpha_{2}\right) \alpha_{3}+\alpha_{1} A_{12}\right], a_{6}=-\left[\left(1-\alpha_{2}\right) \beta+1\right] A_{11}, a_{7}=3 \alpha_{3}$, and $a_{8}=3 \beta A_{11}$.

We first consider the case of $B(1-\xi-\gamma / q)>0$, which can be reduced to (A.21). Then, the first two inequalities in (Case 2) can be reduced to (A.19) and (A.20), respectively. Hence, the determinacy condition is either of the following two.

(Case 1.A) (A.21) and the two strict inequalities opposite to (A.19) and (A.20) hold.

(Case 2.A) (A.19)-(A.22) hold.

We turn next to the case of $B(1-\xi-\gamma / q)<0$. In this case, the determinacy condition is either of the following two.

(Case 1.B) (A.19), (A.20), and the strict inequality opposite to (A.21) hold.

(Case 2.B) (A.22) and the three strict inequalities opposite to (A.19)-(A.21) hold.

Therefore, in Proposition 2, Case I consists of (Case 2.A) and (Case 1.B), and Case II consists of (Case 2.B) and (Case 1.A). 